\title{
A new era of social policy integration? Looking at the case of health, social care and housing
}

\begin{abstract}
Service integration is a global trend aiming to create partnerships, cost-effectiveness and joined-up working across public and third sector services to support an ageing population. However, social policy research suggests that the policy making process behind integration and implementation is complex, contradictory and full of tension. This paper explores social policy integration at the ground-level of services in the health and housing sector within a new integrated model for housing for older people. The paper applies a critical Lipskian approach to show the housing can promote integration for both users and wider stakeholders. Front-line workers were central to service integration, often working to integration principles despite policy changes and uncertainty. Challenges of social policy integration include the gaps between policy and practice and the developing nature of interaction at the ground-level - most notable the role of technology. Technology and digital health platforms could enhance service user and practitioner interactions at the ground-level. The paper calls for renewed focus on policy processes in relation to service integration and consideration of new forms of service user, practitioner and policy maker interaction.
\end{abstract}

Keywords: integration, street-level bureaucracy, housing practice, health, technology, discretion 


\section{Introduction}

A 'silo mentality mindset' (where organisations look inward and resist sharing information and resources with other individuals, departments or organisations) is something that the United Kingdom (UK) and international governments have aimed to break down over the lifetime of social policy implementation, especially in health, with the aim to reduce errors, cost and improve outcomes for citizens (Meessen et al. 2011). Much of the structure and processes in place still revolve around work, welfare, policing, health, housing and education and often these professional silos do not take into account the evolving role of technology and digital data and systems that can facilitate and cross boundaries.

Social policy research has long acknowledged that policy-making and policy implementation is complex, contradictory and full of tension (Keevers et al., 2008). Social policy itself is vague, 'the boundaries of which are ill defined, but the content of which is rich' (Boulding, 1967: 3). This is because 'education, policing, social work, and other vital public services...result from the aggregation of the separate actions of many individuals" who work in these services (Lipsky, 1980[2010]: xiii). The result is a reality where social policy is messy; with no clear boundaries as the issues of welfare, health, housing and education are often integrated and dynamic.

At the same time, social policy as something that is written by government, is moving towards a more integrated agenda internationally and throughout the UK. Through numerous and substantial local government reforms, these traditional silos are being challenged and front-line public service workers are encouraged to be more 'entrepreneurial' (Durose, 2011). The 21 $1^{\text {st }}$ century public servant is expected to be cross-cutting, integrated and a key policy maker (Needham and Mangan, 2014). Policy developments have encouraged services and service delivery to be shared and integrated when possible (Crowe, 2012). Within Scotland, for example, the Public Bodies (Joint working) (Scotland) Act 2014 emphasises the need for joined-up of services to provide integrated health and social care provision to streamline services, thereby reducing public expenditure and enhancing service user outcomes. This agenda has emphasised further integration and inclusion of other public services such as housing.

This paper explores the reality of social policy integration at the ground-level of public and third sector services. Service integration has focused mainly on 'integrated care' between health and social care, but this paper explores the role of housing within this integration agenda 
by presenting the findings from the implementation of a new model of housing for older people in the newly integrated area of housing, health and social care in Scotland.

The paper firstly contextualises public service delivery in an era of integration, questions whether a Lipskian (1980) analysis of street-level bureaucrats is still important in an era of integration and explores the role of technology in policy and practice. The paper presents a mixture of quantitative and qualitative findings (derived from a survey, focus groups, observation and semi-structured interviews) to outline the differences between expectations around integration and the reality of service provision at the ground-level. The implications of the findings highlight the need to renew focus on the social policy process within the integration agenda to take into account new ways of service user, practitioner and policy maker interaction and the increasing role of new technology.

\section{Public service delivery in an era of social policy integration}

From an international perspective, integrating health and social care focuses in particular on preparing for the ageing global population and the concept of 'integrated care'. This is where 'integration of care is seen as a potential mechanism for ensuring joined up service responses to the needs and aspirations of older people, and safe guarding the quality of care received by this often vulnerable group' (Watson, 2012: 5). Benefits of this process have been reported as reducing complexity in accessing health and social care services, enhancing provision, costeffectiveness, reduction in hospital stays, hospitalisation and admission to long term care (Reed et al., 2005).

In the European context, Lloyd and Wait (2006: 7, original emphasis) position integrated care as a system that can address current health and social care system failings such as lack of 'ownership', involvement and communication with the user/patient, 'yet there is a gap between policy intent and practical application'. The concept of integrated care is interpreted differently at the ground-level from front-line providers and can mean more about working with professionals in the field and coordinating activity (Lloyd and Wait, 2006: 9). Nevertheless, the move to integrated care can be observed in several European health systems with a distinction in functional, organisational, professional and clinical integration, which are similar in their experiences of fragmentation and lack of coherence (Delnoij et al., 2002).

Health and social care integration in the UK is discussed in wider terms beyond integrated care' (Goodwin, 2016). Initiatives often have to navigate and overcome existing organisational and funding silos (Goodwin et al., 2014). Service integration is taken up with varying 
approaches within England, Scotland, Wales and Northern Ireland, with a weak evidence base in understanding what works (Kaehne et al., 2017). Health and housing appear to be key areas of perceived policy divergence within the UK devolved structure (although it has been argued that there are more similarities than differences (c.f Greer, 2016).

\section{Widening service integration beyond integrated care}

Within Scotland, one objective of integration is to include wider services, such as housing, to address the challenges in Scotland's ageing population, increase flexibility to meet the physical, mental and social health needs of older people and support early intervention (JIT, 2015; ihub, 2017). However, there has been significant variation across Scotland, and a report from Audit Scotland (2018) noted concerns about the variation of engagement with the third sector (non-profit organisations that are independent of government), which includes housing associations, volunteer and wider care organisations that support older people.

McCall et al., (2018) note that experiences from policy makers, practitioners and older people show that housing has only been part of the periphery of health and social care integration to date. Work is needed to place housing at the heart of integration to support older people in Scotland across all tenures. Some perceive a need to reinforce the role of the third sector to support people making personal choices and changes (person-led change) to enable them to stay well and live independently (The ALLIANCE, 2018).

The policy for Scotland's health and social care agenda also includes a clear technology and digital health stream. The use of technology has potential in the integrated care agenda to facilitate service provision and improve outcomes (Goodwin et al., 2014). The Scottish Government funded a series of initiatives throughout Scotland as part of a Technology Enabled Care (TEC) programme based on a policy where 'digital technology is key to transforming health and social care services so that care can become more person-centered' (Scottish Government, 2016: 23). The Digital Health and Social Care Strategy 2017-22 focuses on supporting health and social care professionals at the front-line who remain central to the delivery of the health and social care integration agenda in Scotland (Scottish Government, 2015, 2016: 27, 2018). For housing, the TEC in Housing Charter is an embodiment of these policy initiatives and focus (SFHA, 2019).

In response to this policy directive, many health, social care and housing organisations are moving towards more integrated services using digital technologies to support older adults' health and care needs. Although the evidence base is mixed or limited for some technologies, 
telehealth and telecare systems which remotely monitor aspects of people's health and care at home, are being piloted and embedded in several National Health Service boards in Scotland. These aim to support older adults to live independently and enable professionals to monitor their health and care needs on a regular basis (Gray et al., 2017; Devlin et al., 2015). However, there are complexities in integrating digital systems and this includes difficulties with data sharing, organisational cultures and context between organizations (Wainwright and Waring, 2004, 2015). Many theories on the impact of Information and Communication Technologies (ICT) on public sector staff exist. Curtailment theory, for example, posits that technology reduces one's ability to be flexible as information must be captured and processed in specific ways. This can remove a certain amount of discretion that street-level bureaucrats hold (Snellen, 2002) and so limit their ability to adapt and make changes. An opposing theory, enablement theory, suggests that technology empowers public servants to be more efficient by giving them access to information needed for decision-making, thereby reducing the number of errors made (Buffat, 2013). While technologies across the health, social care and housing sectors are not wholly integrated as yet, this is the goal for the future, one which could enable front-line professionals to deliver seamless services to all citizens.

Analysis of integration policies in the UK 'demonstrates that there is convergence in policy goals but diversion in policy implementation across the four home nations' (Kaehne et al., 2017: 13, original emphasis). It is clear that the integration agenda at the front-line still has its roots in 'joined-up' approaches to policy, partnership working, and collaboration (Rummery, 2002; Powell and Glendinning, 2002) but the gap between policy and practice has not been central to examination. In the context of health and social care integration, organizational integration has been described as 'rearranging the deckchairs on the titanic' for older people's care (Glendinning and Means, 2004).

Partnership working, and 'joined-up approaches' have been criticized in wider social policy analysis for missing the important role of front-line workers (McCall and Rummery, 2017) and making limited positive outcomes for older people (Brown et al., 2003). Much analysis in this area has focused on local government and public service management (Matthews, 2014) rather than street-level bureaucrats. However, work in this area has shown that key challenges in integrating health and social care are related to front-line practice - such as reliance on hand written notes (Wainwright and Waring 2015) and the re-shaping of services for older people is still very dependent on care relationships (Lewis and West, 2014). Yet, a focus on the workforce within health and social care integration is a neglected area (Stein, 2016). This 
supports a Lypskian analysis looking at service integration at the ground-level, as policy implementation still relies heavily on the interpretation, discretion and actions of those at the front-line.

\section{Taking a Lypskian approach to social policy integration}

A recent refocus on policy implementation has brought street-level practice to the forefront of the policy debate (Taylor and Kelly, 2006; Evans, 2015) and the delivery of health and social care is set against a context of constant social and political change. Michael Lipsky (1980, 2010) linked policy, organisational structures, resources and individual practitioners (streetlevel bureaucrats) as influencing the implementation of policy. This is an example of public and third sector organisations attempting to enact governmental policy, giving insight to the integration agenda in practice. By taking a Lypskian (1980) approach, we highlight the importance of policy in practice i.e. policy as action, on the ground, as made by the interactions of those working at the 'street-level' (what Lipsky refers to as street-level bureaucrats) and the public (or service users, clients).

Lipsky (2010: 3) defines street-level bureaucrats as "public service workers who interact directly with citizens in the course of their jobs, and who have substantial discretion in the execution of their work". Those individuals directly involved in delivering policy at street-level will exercise their discretion in how policies are carried out (Maynard-Moody and Musheno, 2000). Durose (2011: 980) views discretion as a "choice or judgement within recognised boundaries" taken by front-line workers.

There have been many studies that apply the work of Lipsky for analysis purposes, although these have mainly been in public sector areas such as employment services and social work services (Wright, 2003; Evans and Harris, 2004). Lipsky's work is aligned and has influenced ideas of 'boundary spanners', where there is need for front-line professionals to work across boundaries (Aldrich and Herker, D. 1977; Buick et al., 2019). Boundaries in this sense can be formal (organisational) but also informal (organisational culture) and sectoral. Organisational boundaries are a clear mechanism between the public, private and third sectors that are often discussed around ideas of joint-up working, or collaborative governance (Buick et al., 2019). To date, little has been written which draws upon Lipsky's (1980) classic study of street-level bureaucracy in relation to the use of discretion by health and social care professionals and new ways that they interact. However, for those who have utilised the approach, the importance of the discretion of front-line workers in relation to health and housing service provision is 
emphasised (Hoyle, 2011, 2014; Alden, 2015; Harrison, 2016). Lipsky's (1980) approach centres around key themes of discretion, resource limitations, managerial relationships with front-line workers, issues with performance indicators and the differing levels of service that can be offered to different service users. These key themes are common to front-line workers from a variety of services, from a variety of different welfare regimes and other statutory and non-statutory services delivered by third sector and non-profit organizations (Lipsky, 1977; Lipsky and Smith, 1990; Lipsky, 2010).

In regard to the area of health, two areas of Lipsky's approach in particular can been seen to be applicable in the health field: discretion and health-care rationing (Harris, 2016). Hoyle (2014) for example shows that the role of nurses in implementing policy can be very influential via their use of discretion and they can be thought of as "agents of social control" (Lipsky, 2010: 4) despite management reforms in public services (Evans, 2015). In a study of six countries (including Scotland) within health and social care delivery, street-level bureaucrats were important in bridging gaps between services, policy-making, practice and service users (Virtanen et al., 2016). This makes them a key element in looking at areas of service integration between health, social care and housing.

This paper gives insight to a new model of front-line delivery that supports integrated housing, health and social care outcomes for older people. Specifically, this paper looks to answer the following research questions: Does the examination of front-line workers in a new housing delivery model give insight to the process of social policy integration? Does technology shape interactions and the use of discretion for front-line staff?

\section{Methods}

The paper is based on the findings from an evaluation of a new model of older peoples' housing in a housing association based in a disadvantaged, larger urban area in Scotland between March and May 2017. This focus gives extra insight as disadvantaged urban areas may benefit from expert practitioners the most, as they could support 'creative ways to mediate and at times redesign the multidimensional interface between (groups of) people, (formal and informal) policies and (sub)-systems' (van Hulst et al., 2012: 435). The integrated housing model was delivered by local authority and housing association workers (housing associations in the UK are classed as third sector non-profit organisations), who were employed by health, housing and social care services. 


\section{Building an integrated housing model}

The Hub and Cluster Integrated Model for older people's housing had a focus on bringing people and processes together at the front-line, including technology for older residents within housing services. This was designed to support all service users in a specific geographic area in a large urban area in Scotland, with a central 'hub' based in a housing association that supported five strands of wider clustered activity focused on supporting older people living in the area (across different tenures including social and private renters and owner occupiers):

1. Demonstrator apartments

\section{Community Engagement Activity}

3. First through the door initiative

4. Technology and digital inclusion

5. Capital investment and refurbishment

Within strand one, there were two demonstrator apartments within the housing project. These flats were fully refurbished using age and dementia-friendly design (such as good lighting, colour contrast) with integrated technology (floor sensors, virtual personal assistants e.g. Alexa, a virtual personal assistant, home hubs). The demonstrator flats were a platform to test other smaller scale assisted technology interventions focused on preventing injury or ill-health, such as 'magi plugs' (that stop flooding) and kettle tippers (to avoid scalding). Individuals could attend the demonstrator flats and be provided with training on sensory and cogitative impairments and the equipment within them. Around 3,000 training places have been offered to partners (local and wider) including Housing, Health, Social Work, Third and Independent sector staff from across Scotland and England (including three separate delegations from Japan). In terms of the physical development of the demonstrator apartments, the Dementia centre at the University of Stirling and local architectural agencies and Health and Social Care Partnerships also had input into their development.

As part of strand two, there was a dedicated community engagement and activity cocoordinator (EAC), whose role was to developed and identify activities for older adults within the community to engage with and promote active ageing. Strand 3 was an initiative to help support early identification and of an older person's needs via the use of a mobile app tool: First through the Door. This is an app that created interactive elements within the integrated model to employ service and user interaction utilising technology. It focused on wider sector 
professionals, including local health, housing and social workers (and wider services, such as the fire service). The idea for First through the Door was devised by the local Fire and Rescue service where Fire Officers noted that when they were in people's homes quite often they would identify issues out-with their own remit but did not have the knowledge or information to do anything further. A multi-agency working group was established to move this forward with local housing, fire rescue and health groups who agreed the process and development of a mobile web-based app. Stand 4 focused on digital inclusion, mainly this focused on ensuring that older adults in the area had access to computers, iPad and internet. Strand 5, was focusing on planned refurbishment of the local area to ensure that there is local services in place that individuals can access.

\section{Data collection}

Ethical approval was granted by the General University Ethics Pane, University of Stirling. The study was an exploratory study using both qualitative and quantitative data collection methods.

1) Feedback survey: in terms of the demonstrator apartments a feedback survey from the individuals who attended the bespoke training was conducted $(n=1000)$ by the housing association. Analysis of this survey captured views from the participants on the training itself and demographic information on participants from a wide variety of front line services including housing, health and social care.

2) Direct observation: the interactions between service users and housing staff within the housing association buildings were captured through direct observation. An observational framework developed by Robertson and McCall (2020) was adapted to suit this context to allow structured observations.

3) Focus groups: these were conducted with older people living in the new integrated housing model and their family/informal carers. There were two focus groups with 24 people; older adults living in the housing association buildings $(n=20)$, carers $(n=2)$, wider community stakeholders $(\mathrm{n}=2)$. These lasted approximately 1-1.5 hours, with audio and field notes being recorded.

4) Semi-structured interviews: Fifteen semi-structured interviews with front-line workers including housing officers, health and social care practitioners operating in the 'hub and cluster' integrated housing model were conducted. Participant characteristics are not provided due to the risk of anonymity being breached. Interviews lasted on average one hour and were audio recorded. 


\section{Data Analysis}

Survey data were analysed using descriptive statistics within Excel. QSR NVivo 8 was used as a data management tool and to facilitate coding. Thematic analysis (Tong et al., 2007; Ritchie et al. 2013) of interview, focus group and survey data from open-ended text boxes was conducted. The Standards for Reporting Qualitative Research (SRQR) guidelines (O'Brien et $a l ., 2014$ ) were followed to ensure transparency when reporting the qualitative study findings.

\section{Findings}

The following findings focus on front-line workers and their role in service policy integration. The second section focuses on how technology shapes relationships between front-line health, housing and social care staff in an integrated landscape.

\section{Training professionals for an integrated housing model for older adults}

This section of the results, reports findings on the training that professionals received via the demonstrator flats. Different professional groups were brought together and shown the demonstrator flats, which may strengthen interagency links as knowledge about technologies for older adults can be shared in the real-world context of housing for service users and allow different agencies to interact in this space and to gain greater understanding of the roles of different staff groups in supporting older adults. The survey taken by staff attending training at the flats, noted that $99 \%$ of all attendees rated the training as excellent or very good. Overall, participants reflected on the why they found these flats so useful:

"For me, the demonstrator flats have been absolutely fantastic. Housing staff, social care, staff, everybody who has come through the door is really impressed. Find it really interesting, find it really useful. The smallest things can make a difference. It's getting them to think about things, when they go through the door of someone's home" (service manager).

"...it's about creating a culture of links within the staff here, and learning about local resources. So we take all the GPs, nurses, admin staff out to visit local resources... One of those days I took the whole team from the GP practice to the demonstrator flats and the feedback we had here from the staff was fantastic. They were really impressed by them" (front-line worker). 
It was generally felt that these demonstrator apartments could enable professional interaction and best practice in housing services to be developed across different public sectors.

"benefits for individuals and the wider community as a lot of effort was made to understand all the inputs into the area and to improve the connections between different agencies [list given] in a way to offer prospects of their efforts being better coordinated and in that regards I think this is laudable and has benefits that staff are much more aware of each other that they would have customarily been and I'm sure this benefitted individuals in the area" (front-line worker).

"I think having joint working days with other agencies will help in further developing of [the demonstrator flats]. Multi-agency days could work better and more people from the community coming to see the project is better as well" (front-line worker).

One of the successes of the demonstrator flats related to their ability to be a space for partners to interact and showcase how the technology can be used. Most of the potential was seen in raising awareness and the positive impact that had on front-line practice.

"People [who have used the flats] realise what it is like to be an older person. Even our health and social care colleagues have been amazed by some of the stuff that is in there" (front-line worker).

New ways of partnership working were evidenced as the model (in particular the demonstrator flats) encouraged innovative solutions to promoting the health and safety of communities and helping diverse services work together. For example, one interview participant described how the project had influenced their own safety developments. A new safety house had been developed following engagement with the demonstrator flats:

"We unashamedly copied what [they] are doing” (interview with fire service professional)

This could arguably show front-line workers as developing their role as street-level bureaucrats in the Lypskian sense but also as 'boundary spanners' (Buick et al., 2019). For example, while conducting training in one demonstrator flat, a group of attendees who were there for the training gave feedback to the housing staff that the clock they were using was not fit for purpose. With this feedback, the housing staff presented a range of clocks to support the training of other professionals support personalised support within older people's health and housing. From this interaction, the service was developing a new type of partnership working, based on "mutual benefits" in regards to awareness raising and training. The Fire and Rescue 
service were planning, for example, to invite people to the safety house, raise their awareness but also 'swap' expertise with those agencies.

This demonstrator element of the integrated housing model created a new technology enhanced space that seemed to facilitate inter-professional interaction and learning, which may facilitate future practice around integrated services.

\section{New community-level professional's and their role in service integration}

Outside the demonstrator flats, financial resources were placed into community engagement rather than capital refurbishment (due to the capital refurbishment being delayed). This aimed to facilitate integrated housing services through the introduction of a new role (an Engagement and Activities co-ordinator (EAC) employed by the housing association) that worked directly with service users. They made links with local services and ran a variety of activities such as cultural and sporting events and facilitating access to services. For service users, the community activities (such as walking, football, exercise classes, iPad training, and hairdressing) and the links to healthcare of the integrated housing model were seen as positive:

"... Since we got to have [the community officer] it has opened our eyes a bit more to other things... More interactive. And doing the same things but on an outside scale" (focus group 2).

"Community engagement post has been a huge success. There are other places that have these, but this one has added more. Such as links with GPs, that has been unique"(front-line worker).

Those older adults living in the new integrated housing model were protective of the new activities and the EAC involved. For some individuals, it was the only interaction with other people in a social sense outside of the family:

"We love the staff. We call them the A team" (focus group 1).

"They are exemplary here. The team in here... Being in [residential area] changed our lives in here... Staff are good, capable and dementia aware... [It was] a turning point being in here. She would be dead if she was not in here" (Carer taking part in focus Group 2)

Front-line staff in general, alongside the EAC, were key to the integrated housing model as they brought the services together at the ground-level to link housing, health and social care outcomes: 
"A couple in their 80s was at a crisis stage because they were caring for each other. Lady had an alcohol problem in her 80s and the other person has not had a shower for about 4 months. I was able to put a service in place and this is actual in-depth support through sign posting" (front-line worker).

"I was speaking to somebody in her 70s and saw struggling to cut their own toenails. After talking to her, I arranged a chiropodist" (front-line worker).

"I was able to sign post a relatively young person in 50s who was diagnosed with dementia to walking football, which really change his life. I also took him and his wife to the demonstrator flats and encourage them to continue a normal life and especially not to deskilled the person with dementia" (front-line worker).

These examples highlight that integration work at the ground level is firstly about individual, small scale activities, facilitated by front-line workers.

\section{Front-line interactions through technology}

Technology was an aspect of the integrated housing model, yet Lipsky's (1980) original analysis mainly included the face-to-face interactions of street-level bureaucrats and service users. This is important to examine as modern day health, social care and housing staff employ discretion in the range of strategies used to engage clients, including interacting electronically via technology (O'Connor et al., 2016). The results indicate that technology can shape the interactions of front-line workers in a number of ways. Both curtailment theory (Snellen, 2002) and enablement theory (Buffat, 2013) seemed to be present in the new integrated housing model. For example, the First through the Door app allowed service users to have more control of what professionals and agencies they interacted with. The app also provided details of services that could be accessed by service users to allow individuals to refer themselves to services for support by using a mobile phone, tablet computer at home. It also allowed the front-line service workers themselves to know who service users were interacting with as this could be seen on the app. This enabled service users, to have an element of control within this process and they are involved in the process of accessing support for their needs.

Curtailment however, was apparent as some areas had poor Internet access, which seemed to restrict front-line staff's discretion in using certain technologies with service user and gathering necessary housing, health or social care data. Here in the example below, the front-line worker is adapting the technological support for the contextual challenges in that area: 
"They met the criteria for referral to the project, they were over 50, socially isolated, there were some problems as well around alcohol. And there was also problems related to extended family and the impact the patient was having on their family due to isolation and developing needs as they got older. So providing people for support for people that age and linking to a specific organisation that caters to people in that age group the project was perfect for this area" (Front-line worker)

"The project for me here [in this area] was essential for me for accessing specific targeting support for people in that age group. In order to help support them to remain in their homes. And for the family and the carer" (front-line worker)

Another aspect was the quality of information that certain technologies provided. For example, some front-line workers felt that remote monitoring of physical and environmental parameters in people's homes did not fully reduce the risk that something could be wrong with older service users, potentially limiting their discretionary powers.

"Some of the basics, like access to Wi-Fi, that is not disadvantaging people due to cost reasons. So in that block they have access to Wi-Fi and other disadvantaged areas don't have that access" (front-line worker).

"certainly in terms of providing some reassurance it would give you some greater reassurance on what an individual is doing but doesn't remove the risk entirely" (service manager).

In contrast, enablement was apparent in the First through the Door app, as it appeared to help front-line staff identify local health, social care and housing resources and services for clients. The app enabled cross agency working and collective responsibility to ensure that all needs e.g. care, social, safety, for clients were met, demonstrating technology can facilitate the use of discretionary actions by front-line staff. There was a suggestion that this created a shift in culture within housing services and people knew who to contact in other agency:

"I go to forums in social care, and they are always referring to it as they find it really useful. They look at the app, go to housing, and they know who to contact" (front-line worker).

"So for us, we would use it for health visits but I know other services found it extremely useful as they don't have the same links and the same knowledge that we would maybe have when we go into a tenant's home and help them sustain their tenancy" (service manager). 
Technology at times seemed to help front-line workers in their roles, facilitating a certain amount of discretion when coordinating and delivering care.

\section{Discussion}

The integrated housing model helped to support discretion and decision-making for staff at the ground-level through creating new spaces and opportunities for interaction. Staff had more autonomy to develop aspects of the service model (for example the demonstrator flats and First through the Door) that enabled interactions between different health and housing professionals. The findings suggest an important role of front-line professionals in creating new spaces that encourage new working relationship and therefore service integration. However, we found in this study that integration was reliant on front-line members of staff who were often working to integration principles.

In response to the research questions, this paper provides insight to the process of social policy integration and highlights the potential of technology to shape new spaces and interactions for front-line staff. The assumptions behind interaction from a Lipskian perspective are often based on face-to-face interaction. However, as this model shows this interaction can also take place on a number of levels, with a role for new spaces and technology. It also indicates there is room to implement personal values and choices in the interactions with service users. The integrated housing model worked as a facilitator and platform for agencies to come together and to develop working relationships.

This paper has shown that Lipsky's (1980) street-level approach is still applicable to changing and integrated services, such as housing services. Front-line workers were seen to be an important element that created service integration at the ground-level. The integrated housing model facilitated interagency working, when this may not have traditionally happened in between housing and health services. This current paper adds to Lipsky's (2010) analysis in highlighting the important role of front-line professionals in interpreting and implementing policy but emphasises a need to also include the developing nature of interaction at the ground level - most notable the role of technology. Key reports that have focused on front-line delivery (for example From the Ground Up, Department for Health 2000) often focus on design and delivery of services, management, governance workforce and workplace management and infrastructure. Technology and platforms for communication between professionals and service users have had much less attention. The model evaluated here shows that technology 
can have a role for both supporting inter-agency working and service user involvement in their health, social care and housing provision.

The lens in which service integration occurs, with a focus on preparing for an ageing population, was also an important dynamic in the outcomes and aims of the integrated housing model. Walker (2018: 269) calls for a new strategy for ageing - a social policy on ageing - and the debate on service integration links well with the idea of ageing as 'malleable' and the call for 'a new policy approach that is effective in changing social institutions and individual behaviour to reduce risks will have absolute benefits for both ageing people and populations'. The positive outcomes from this model (for example the service user involvement, partnerships with wider health services) were led by users and professionals at the ground-level (albeit in a generally positive policy context towards integration) who were able to take the collective approach called for by Walker (2018) and put active ageing first by mobilising different services.

This research focuses on the ways in which Lipsky could be applied in a digital era of integrated health, housing and social care. The findings indicate that they key element of discretion can still be a part of service delivery. Furthermore, the integrated housing model's success, from a service user perspective, was the activity and interaction (e.g. walking football, hairdressing, IPad training) that was facilitated from front-line workers. However, the model also presents the potential for an evolving process for interaction between front-line workers and service users linked to technological and digital inclusion, especially when the technological interventions enhanced communication between services and users (for example, the First through the Door app). This finding brings a new insight to the policy strategy in Scotland that claims that 'digital technology is key to transforming health and social care services so that care can become more person-centered' (Scottish Government 2016: 23). In the findings, digital technology was important in regards to increasing access, communication, connections and service user empowerment.

In this study, technology was shown to shape interactions and the use of discretion for frontline staff although on an individual level. Technology at times seemed to help front-line workers in their roles, facilitating a certain amount of discretion when coordinating and delivering care. Technological strands within the model were strongest when used to facilitate and enhance service users' face to face interactions. The digital inclusion strand did not circumvent front-line staff and service user interaction. Instead, it became another tool and 
channel to enhance it communication through new routes, opportunities and activities between staff and service users. Therefore, although interaction has changed from Lipsky's seminal work in 1980, the core foundation and importance of that front-line worker and service user interaction still remains. Service integration between housing, health and social care is reliant of the facilitation of front-line workers who can utilise discretion to circumvent and develop social policy boundaries.

In regards to 'boundary spanners' there was evidence of crossing over organisational and sectoral boundaries, and these were facilitated by front-level workers. This aligns with conventional integration models, as boundary spanning work across organisations, groups or sectors requires key boundary spanning individuals performing multiple roles (Buick et al., 2019). The difference with this integrated housing model was the explicit role of technology in supporting integration and multiple roles by linking people who were not linked before. New professional roles (such as EACs) that facilitate integration seem to be enablers and could extend and enhance current knowledge that focuses partnership working on the strategic/managerial level (Matthews, 2014).

Although this model has positive outcomes, integration will still be a challenge without substantial resource transfer (Glendinning and Means 2004). Glendinning and Means (2004) are focused particularly on health and social care but this also applied to the housing sector as well. The finding show that front-line workers are facilitating change and making integration work, but this is on a small scale and more investment is needed to break wider barriers between health, housing and social care.

\section{Conclusion}

This paper investigated the delivery of social policy integration at the ground-level of public services in the housing sector. The findings highlight service integration and innovation within an integrated housing model that focused on older people and explored how the 'silo mentality mindset' (Meesen et al. 2011) might and can be broken down. The study focused on the use of discretion at the ground-level for more effective inter-agency working. The joint-working between health, social care and housing via the demonstrator flats for training around design and technology, community engagement partnerships, promoting active aging, technology and digital inclusion had reported positive outcomes for service users. The findings suggest that several of the successful elements of service integration were due to front line discretion and the ability for different professionals to engage with each other. . 
This study has given insight into how front-line workers can create and facilitate new spaces for service user and inter-agency learning and interaction. Lipsky's approach to understanding street-level bureaucrats and the role of discretion was clearly applicable in highlighting the role of front-line workers in interpreting and implementing policy and adapting to multiple expectations around the integration agenda. However, the paper also indicates that how this interaction occurs is evolving, with focus on the role of technology in facilitating interaction in and between services and with service users. This has implications in how we understand the policy process, the range of actors involved and how the integration agenda can be developed in the UK and internationally.

\section{Abbreviations}

Integrated Authorities (IAs); National Health Service (NHS); Technology Enabled Care (TEC); United Kingdom (UK)

\section{References}

Alden, S. (2015), 'Discretion on the frontline: the street level bureaucrat in English statutory homelessness services', Social Policy and Society, 14, 1, 63-77.

Aldrich, H., and Herker, D. (1977), 'Boundary spanning roles and organization structure', Academy of Management Review, 2, 2, 217-30.

ALLIANCE (2018), 'We need to talk about integration', www.alliance-scotland.org.uk [accessed 20.09 2018].

Audit Scotland (2018), 'What is integration? A short guide to the integration of health and social care services in Scotland', http://www.audit-scotland.gov.uk/report/what-isintegration-a-short-guide-to-the-integration-of-health-and-social-care-services-in [accessed $20.092018]$.

Boulding, E. (1967), ‘The Boundaries of Social Policy', Social Work, 12, 1, 3-11

Buffat, A. (2013), 'Street-level bureaucracy and E-government', Public Management Review. $17,1,149-161$ 
Buick, F., O’Flynn, J. and Malbon, E. (2019), 'Boundary challenges and the work of boundary spanners', in H. Dickinson, C. Needham, C. Mangan and H. Sullivan (eds.), Reimagining the Future Public Service Workforce. Singapore: Springer, 21-38.

Brown, L., Tucker, C., Domokos, T., (2003), 'Evaluating the impact of integrated health and social care teams on older people living in the community', Health and Social Care in the Community, 11, 2, 85-94

Crowe, D. (2012), 'Catalyst councils: a new future for local public service delivery', http://www.localis.org.uk/research/catalyst-councils [accessed 16.09.2015].

Delnoij, D., Klazinga N. and, Glasgow, I. (2002), 'Integrated care in an international perspective', International Journal of Integrated Care, 2, 2,

Department of Health (2000), 'From the ground up: a report on integrated care design and delivery', England: Institute of Public Care, Integrated Care network and Community Health partnerships.

Devlin, M., McGee-Lennon, M., O’Donnell, A., Bouamrane, M., Agbakoba, R., O’Connor, S. and Browne, S. (2015), 'Delivering digital health and well-being at scale: lessons learned during the implementation of the Dallas program in the United Kingdom', Journal of the American Medical Informatics Association, 23, 1, 48-59.

Durose, C. (2011), 'Revisiting Lipsky: front-line work in UK local governance', Political Studies, 59, 4, 978-95

Evans, T., and Harris, J (2004), 'Street-level bureaucracy, social work and the (exaggerated) death of discretion', The British Journal of Social Work, 34, 6, 871-95.

Evans, T. (2015), 'Street-level bureaucracy, management and the corrupted world of service', European Journal of Social Work, 19, 5, 602-15.

Glendinning, C. and Means, R. (2004), 'Rearranging the deckchairs on the Titanic of longterm care - is organizational integration the answer?', Critical Social Policy, 24, 4, 435-57.

Goodwin, N., Dixon, A., Anderson, G. and Woodchis, W. (2014), 'Providing integrated care for older people with complex needs', London: The Kings Fund. 
Goodwin, N. (2016), 'Understanding integrated care', International Journal of Integrated Care, 16, 4, 1-4.

Gray, S., Mercer, S., Palen, T., McKinstry, B. and Hendry, A. (2017), 'eHealth advances in support of people with complex care needs: case examples from Canada, Scotland and the United States', Healthcare quarterly, 19, 2, 29-37.

Greer, L. (2016), 'Devolution and health in the UK: policy and its lessons since 1998', British Medical Bulletin, 118, 1, 16-24.

Harrison, S. (2016), 'Street-level bureaucracy and professionalism in health services', in Hupe, P. and Hill, M. (eds) Understanding street-level bureaucracy, London: Policy Press, $61-77$

Hoof, J. (2010), Ageing-in-Place. The integrated Design of Housing Facilities for People with Dementia, Amsterdam: Eindhoven University Press.

Hoyle, L. (2011), New public management and nursing relationships, Stirling: University of Stirling.

Hoyle, L. (2014), 'I mean obviously you're using your discretion: nurses use of discretion in policy implementation', Social Policy and Society, 13, 2, 189-202

ihub (2017), 'Improvement hub impact report 2016-2017', https://ihub.scot/media/1282/20170920-ihub-impact-report-agreed-final.pdf [accessed 30.04.2018].

Hulst, M., Graaf, L. and Brink, G. (2012), 'The work of exemplary practitioners in neighbourhood governance', Critical Policy Studies, 6, 4, 434-51.

Joint Improvement Team (2015), 'Health and social care integration: guide for housing practitioners', http://www.jitscotland.org.uk/resource/health-and-social-care-integration-aguide-for-housing-practitioners-briefing-no-2/ [accessed: 30.04.2018].

Kaehne, A., Birrell, D., Miller, R. and Petch, A. (2017), 'Bringing integration home: policy on health and social care integration in the four nations of the UK', Journal of Integrated Care, 25, 2, 84-98 
Keevers, L., Treleaven, L. and Sykes, C. (2008), 'Partnership and participation: contradictions and tensions in the social policy space', Australian Journal of Social Issues, $43,3,459-77$.

Lewis, J. and West, A. (2014), 'Re-shaping social care services for older people', Journal of Social Policy, 43, 1, 1-18.

Lipsky, M. (1977), 'Street-level bureaucrats and institutional innovation: implementing special education reform', Harvard Educational Review, 47, 2, 171-97

Lipsky, M. (1980), Street-level bureaucracy: dilemmas of the individual in public services, London: Harvester Wheatsheaf.

Lipsky, M. and Smith, S. (1990), 'Nonprofit organisations, government and the welfare state', Political Science Quarterly, 104, 4, 625-48.

Lloyd, J. and Wait, S. (2006), Integrated Care - A Guide for Policymakers. London: International Longevity Centre.

Matthews, P. (2014), 'Being strategic in partnership: interpreting local knowledge of modern local government', Local Government Studies, 40, 3, 451-72.

Maynard-Moody, S. and Musheno, M. (2000), 'State agent or citizen agent: two narratives of discretion', Journal of Public Administration Research and Theory, 10, 2, 329-58.

McCall, V. and Rummery, K. (2017), 'The theory and practice of welfare partnerships: the case of the cultural sector', Social Policy and Administration, 51, 1, 56-75.

McCall, V., Eadie, J., Lovatt, M., MacIntyre, Z., Phillips, J., Porteus, J., Robertson, J., Rutherford, A., Sixsmith, J., Wallman, J. and Woolrytch, R. (2018), 'Housing and ageing: Linking strategy to future delivery for Scotland, Wales and England 2030', Scotland: Scottish Universities Insight Institute.

Meessen, B., Kouanda, S., Musango, L., Richard, F., Ridde, V. and Soucat, A. (2011), 'Communities of practice: the missing link for knowledge management on implementation issues in low-income countries?', Tropical Medicine \& International Health, 16, 1007-14. 
Mooney, G. and Poole, L. (2004), 'A land of milk and honey'? Social policy in Scotland after Devolution', Critical Social Policy, 24, 4, 458-83.

Needham, C. and Mangan, C. (2014), The $21^{\text {st }}$ century public servant, Birmingham: University of Birmingham.

O’Brien, BC., Harris, IB., Beckman, TJ., Reed, DA. and Cook, DA. (2014), 'Standards for reporting qualitative research: a synthesis of recommendations', Academic Medicine, 89, 9, 1245-51.

O’Connor, S., Hanlon, P., O’Donnell, A., Garcia, S., Glanville, J. and Mair, F. (2016), 'Understanding factors affecting patient and public engagement and recruitment to digital health: a systematic review of qualitative studies', British Medical Council, Medical Informatics and Decision Making, 16,120, 1-15.

Powell, M. and Glendinning, C. (2002), 'Introduction', in C. Glendinning, M. Powell and K. Rummery (eds.), Partnerships, New Labour and the Governance of Welfare, Bristol: Policy Press, 1-14.

Reed, J., Cook, G., Childs, S. and McCormack, B. (2005), 'A literature review to explore integrated care for older people' International Journal of Integrated Care, 5, 1

Ritchie, J., Lewis, J., Nicholls, C.M. and Ormston, R (2013), Qualitative Research Practice, London: Sage

Robertson, J. and McCall, V. (2020), 'Facilitating creativity in dementia care: the coconstruction of arts-based engagement', Ageing \& Society. 40, 6, 1155-1174

Rummery, K. (2002), 'Towards a theory of welfare partnerships' in C. Glendinning, M. Powell and K. Rummery (eds), Partnerships, New Labour and the Governance of Welfare, Bristol: Policy Press, 229-45

Scottish Government (2014), 'The Public Bodies (Joint Working) (Scotland) Act 2014', Edinburgh: The Scottish Government, http://www.gov.scot/Topics/Health/Policy/AdultHealth-SocialCare-Integration/About-the-Bill [accessed 21.10.2016]. 
Scottish Government (2015), 'eHealth Strategy 2014 - 2017’, Edinburgh: The Scottish Government, http://www.gov.scot/Publications/2015/03/5705 [07.12.2016].

Scottish Government (2016), 'Health and Social Care Delivery Plan', Edinburgh: The Scottish Government, http://www.gov.scot/Resource/0051/00511950.pdf [accessed 10.09.2018].

Scottish Government (2018), 'Scotland's Digital Health and Care Strategy - Enabling, Connecting and Empowering', Edinburgh: The Scottish Government, http://www.gov.scot/Publications/2018/04/3526/downloads\#res-1 [accessed 10.11.2018].

SFHA (2019) 'TEC in Housing Charter', https://techousing.co.uk/ [accessed 01.11.19].

Snellen, I. (2002), 'Electronic governance: implications for citizens, politicians and public servants', International Review of Administrative Sciences. 68, 2, 183-98

Stein, K. (2016), 'Developing a competent workforce for integrated health and social care: what Does It Take?', International Journal of Integrated Care, 16, 4, 9-11

Taylor, I. and Kelly, J. (2006), 'Professionals, discretion and public sector reform in the UK: re-visiting Lipsky', International Journal of Public Sector Management, 19, 7, 629-42.

Tong, A., Sainsbury, P. and Craig, J. (2007), 'Consolidated criteria for reporting qualitative research (COREQ): a 32-item checklist for interviews and focus groups', International Journal for Quality in Health Care. 19, 6, 349-57.

Virtanen, P., Laitinen, I. and Stenval, J. (2016), 'Street-level bureaucrats as strategy shapers in social and health service delivery: Empirical evidence from six countries', International Social Work, 61, 5, 724-737.

Wainwright, D. and Waring, T. (2004), 'Three domains for implementing integrated information systems: redressing the balance between technology, strategic and organizational analysis', International Journal of Information Management, 24, 4, 329-46

Wainwright, D. and Waring, T. (2015), Competing or Collaborating Systems: Are we Ready for Health and Social Care Integration?, UK: Oxford University. 
Walker, A. (2018), 'Why the UK needs a social policy on ageing', Journal of Social Policy, $47,2,253-73$

Watson, J. (2012), 'Integrating health and social care from an international perspective', London: The International Longevity Centre, http://www.ilcalliance.org/images/uploads/publicationpdfs/Integrating_health_and_social_care_from_an_international_perspective.pdf [accessed 10.09.2018].

Wright, S. (2003), Confronting unemployment in street-level bureaucracies: job centre staff and client perspectives, Stirling: University of Stirling. 